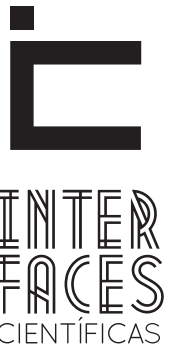

EDUCAÇÃO

ISSN IMPRESSO 2316-333X

ISSN ELETRÔNICO 2316-3828

Dossiê

\title{
A LIVRARIA DE ANTONIO CAZIMIRO LEITE [1794]
}

Vera Maria dos Santos ${ }^{1}$

\section{RESUMO}

Em Sergipe os livreiros e leitores coloniais deixaram poucos indicativos acerca dos seus livros e das suas leituras. Entretanto, através de seus inventários post-mortem podemos recuperar os indícios dos mesmos. A proposta deste artigo, sob os auspícios do inventário post-mortem de Jozefa Maria de Siqueira, falecida em 1794, é a de compor o perfil do seu marido e inventariante, o livreiro Antonio Cazimiro Leite, morador da cidade de São Cristóvão da Capitania de Sergipe Del Rey, que tinha em sua livraria quinhentos livros. Esse inventário, tratado mediante o crivo da história cultural e do entendimento de Darnton (1990) que tem o livreiro como um agente cultural, importante no processo de difusão e de circulação dos materiais impressos, nos dá subsídios para a compreensão da existência de um mercado consumidor desses bens culturais no século XVIII.

\section{PALAVRAS-CHAVE}

Livros. Livraria. Inventário. Sergipe. 


\section{ABSTRACT}

In Sergipe, colonial booksellers and readers left few indications about their books and their readings. However, through their post-mortem inventories, we can retrieve the evidence thereof. The purpose of this article, under the auspices of post-mortem inventory by Jozefa Mary Smith, who died in 1794, is to compose the profile of her husband and executor, the bookseller Cazimiro Antonio Leite, who was a resident of the city of São Cristóvão in the Captaincy of Sergipe Del Rey. He had five hundred books in his library. That inventory mentioned above was handled through the sieve of history and cultural understanding by Darnton (1990) who sees the bookseller as an important cultural agent in the dissemination and circulation of printed materials process. That theoricist gives us the background information to understand the existence of a consumer market of cultural goods in the eighteenth century.

\section{KEYWORDS}

Books. Bookstore. Inventory.

\section{RESUMEN}

En Sergipe, libreros y lectores coloniales dejaron pocos indicativos acerca de sus libros y de sus lecturas. Sin embargo, por medio de sus inventarios post-mortem podemos restablecer los indicios de ellos. La propuesta de este artículo, bajo los auspicios del inventario post-mortem de Jozefa Maria de Siqueira, fallecida en 1794, es la de componer el perfil de su marido y albacea, el librero Antonio Cazimiro Leite, residente de la ciudad de São Cristóvão da Capitania de Sergipe Del Rey, que tenía en su librería quinientos libros. Este inventario, bajo la criba de la historia cultural y el entendimiento de Darnton (1990), que considera el librero como un agente cultural importante en el proceso de difusión y de circulación de los materiales impresos, nos da subsidios para la comprensión de la existencia de un mercado consumidor de eses bienes culturales en el siglo XVIII.

\section{PALABRAS-CLAVE}

Libros. Librería. Inventario.

\section{INTRODUÇÃO}

Esse artigo é parte da pesquisa que desenvolvi no Doutorado em Educação da Universidade Federal de Sergipe, sobre a mulher de posses e a instrução dos órfãos da Capitania de Sergipe Del Rey. As fontes que deram suporte para a realização desse trabalho foram os inventários judiciais setecentistas. Procurando nesses documentos os indícios sobre o tema anunciado encontrei o registro de uma livraria nos anos setecentos, que é um dado relevante para compor a educação do período colonial sergipano.

Em Sergipe os livreiros e leitores coloniais deixaram poucos indicativos acerca dos seus livros e das suas leituras. Entretanto, através de seus inventários post-mortem podemos recuperar os indícios e resíduos marginais dos mesmos. A proposta deste artigo, sob os auspícios do inventário post-mortem de Jozefa Maria de Serqueira, falecida em 1794, é a de compor o perfil do seu marido e inventariante, o livreiro Antonio Cazimiro Leite, morador da cidade de São Cristóvão, Capitania de Sergipe Del Rey.

Esse inventário, tratado mediante o crivo da História Cultural e do entendimento de Darnton (1990) que tem o livreiro como um agente cultural, importante no processo de difusão e de circulação dos materiais 
impressos, nos dá subsídios para a compreensão da existência de um mercado consumidor desses bens culturais no século XVIII, apesar da historiografia sergipana revelar que sua população era essencialmente rural e pouco letrada.

O referido inventário também nos possibilita perceber a importância da livraria como ponto comercial da vida são-cristovense setecentista, na medida em que expõe a sua localização, sua construção arquitetônica, a descrição e a avaliação dos seus bens. Tais elementos nos possibilitam apreender o seu perfil sócio-econômico-cultural e conseqüentemente, o grau de refinamento da família de Antonio Cazimiro Leite.

Diante do exposto, compreende-se que os inventários contêm dados importantes sobre o cotidiano das famílias e são em geral, documentos raros em Sergipe nesse período. Para Araújo (1999), "o inventário é um documento muito peculiar, onde se sumariam todos os bens do falecido para, pela atribuição de valores a esses bens, chegar-se ao termo de partilha entre os herdeiros" (ARAÚJO, 1999, p. 239). Desse modo, "[...] o inventário revelou-se uma extraordinária fonte de informações no que tange à constituição de bibliotecas - talvez a única com que pudéssemos contar para a riqueza de material que recolhemos" (ARAÚJO, 1999, p. 239). Esse entendimento de Araújo, também pode ser aplicado na análise e constituição de livrarias, com é o caso do inventário de Josefa Maria Serqueira, que consta um estabelecimento dessa natureza.

No trato com as fontes judiciais, é preciso atentar que ao analisarmos esse tipo de documentação devemos captar o que está posto nas entrelinhas de sua escrita porque "[...] por mais que o pesquisador tente se aproximar de uma verdade sobre o passado, apostando no rigor metodológico, permanece sempre fluídos os pedaços de história que se quer reconstruir" (LOPES, 2001, p. 77).

A cidade de São Cristóvão situada ao leste do Estado, próxima a foz do Rio Sergipe foi fundada em 1590, por Cristóvão de Barros.
[...] foi conhecida até o século XVIII com a denominação de Sergipe d'El Rei e permaneceu como sede da Comarca única de Sergipe até 1832, quando da execução do Código do processo Penal, que desmembrou a Comarca de Sergipe em três Comarcas: São Cristóvão, Estância e Santo Amaro das Brotas (Cf. SERGIPE, 2005, p. 11).

Na visão de Nunes (1996) as atividades econômicas desenvolvidas na São Cristóvão setecentista eram essencialmente agrícolas e os seus moradores nas "[...] viviam nas casas-grandes dos engenhos e fazendas, nas modestas habitações dos sítios ou nas choupanas, casebres e senzalas levantadas nas proximidades da residência do senhor de terra" (NUNES, 1996, p. 171).

A cidade de São Cristóvão, segundo Nunes (1996), impunha-se apenas por sua função política, como capital da Capitania, muito embora, economicamente, não era o núcleo mais próspero e ainda tinha um agravante de não,

\section{[...] dispor de porto que estimulasse as atividades econômicas, tomou-se uma cidade de burocratas e religiosos. Os primeiros eram os responsáveis pelo funcionamento da máquina político-administrativa: Capitão-mor, Ouvidor, Tabelião, Inquiridor, Contador e Distribuidor, Alcaide, Carcereiro, Almotacés. Os se- gundos decorriam de ali se encontrar a sede do Vigá- rio-Geral e existirem os conventos dos Carmelitas e Franciscanos (NUNES, 1996, p. 171).}

$\mathrm{Na}$ verdade, a análise realizada por $\mathrm{Nu}$ nes(1996), reflete como mencionei anteriormente, uma realidade presente na historiografia sergipana, que no período colonial Sergipe era apenas “[...] uma sociedade em formação, sem núcleos urbanos importantes [...] dispersa no interior em decorrência das atividades econômicas dominantes [...]" (NUNES, 1996, p. 263). No caso de São Cristóvão, tal realidade não se apresenta diferente, a cidade era essencialmente voltada para as atividades agrícolas e seus habitantes rurais moravam em modestas habitações, distantes uma das outras. Considerando essa realidade, quem se interessaria em comprar livros? 
Mas examinando os pormenores, os resíduos ou dados marginais, presentes no texto de Nunes (1996), é possível acreditar que São Cristóvão não era uma cidade pequena, apenas voltada para a agricultura, era conforme essa autora, um centro administrativo, onde ocorriam as decisões político-administrativas da Capitania. Aliada a função atribuída à cidade temos ainda que considerar existência da Igreja Matriz, da Capela de N. Sra. Dos Pretos, do Convento das Carmelitas Calçadas e dos Franciscanos e ainda existiu a Casa da Misericórdia. Convém ressaltar que no Brasil colonial, poucos lugares tinham Casa de Misericórdia instituição que sobressaía na assistência aos enjeitados, muitas possuidoras de roda, como a de Salvador, instituída em 1726 e a do Rio de Janeiro, em 1738 (FARIA, 1998, p. 68). É importante considerar também que muitos dos habitantes de São Cristóvão "[...] pretendem ser muito distintos pela nobreza de seus nascimentos. É verdade que ali habitam muitas famílias puras e podem bem numerar-se mais de 1.500 brancos naturais da Europa e descendentes de europeus, seus primeiros povoadores" (NUNES, 1996, p. 173). Em termos da população, a autora citada afirmou que em 1757, a cidade tinha o registro de 390 fogos e 1.557 habitantes.

Os elementos acima citados refletem a existência de um ambiente urbano, o que nos possibilita olhar a São Cristóvão setecentista sob outra lente. A lente de um centro político e administrativo, com diversidade de serviços, onde transitaram intelectuais, onde circularam idéias e capital financeiro.

\section{ANTONIO CAZIMIRO LEITE E A SUA LIVRARIA NA CIDADE DE SÃO CRISTÓVÃO}

Antonio Cazimiro Leite foi casado com Dona Jozefa Maria de Serqueira ${ }^{2}$, que faleceu em 1794, quando Antonio Cazimiro tinha 56 anos de idade. As despesas com os ritos funerários ${ }^{3}$ da sua esposa demonstram a devoção da sua família à religião católica, que também pode ser observada pelos pedidos de missas de corpo presente, presença dos padres de assistência de ofício. Não somente as despesas do funeral atestam a devoção católica do casal, mas a presença de imagens sacras que integram a relação dos bens do casal como: imagem de Santo Antonio pequeno, imagem de Santo Cristo, imagem da Senhora Santa Anna e uma santa de marfim. Era comum, "[...] nas paredes de muitas casas coloniais, saindo do quarto,

2 Disponível no Arquivo Geral do Poder Judiciário.

3 Na página 22 do inventário de Josefa Maria de Serqueira encontrei o valor total do funeral, quando foi pedido que se abatesse nas despesas do funeral, orçado em $128 \$ 000$ réis, o valor de $53 \$ 000$ réis, correspondente a uma venda de 68 tomos de livros de uma História Ecclesiastica. lá estavam para ser venerados e saudados os quadros os "registros" dos santos de maior devoção dos donos da morada" (MOTT, 1997, p. 167). Ainda segundo esse autor o oratório, "[...] funcionava como uma espécie de relicário, onde eram conservados, além de eventuais relíquias "verdadeiras" do Santo Lenho, da coluna onde Cristo foi açoitado, pedacinhos de osso de algum santo, e eventualmente até um bocadinho do leite em pó de Nossa Senhora" (MOTT, 1997, p. 167).

Todo esse material religioso fazia parte dos costumes domésticos das famílias da época em que homens e mulheres devotos decoravam os seus aposentos com imagens e oratórios de todos os tipos e tamanhos e faziam as suas orações diárias em casa, cumprindo os rituais e até as horas canônicas.

A variedade e a quantidade de bens, arrolados no inventário de Jozefa Maria de Serqueira e ainda as dívidas 
de vendas, mostram que a sua família tinha uma posição privilegiada, no microcosmo social sãocristovense, com uma fortuna avaliada em 1: $860 \$ 674$ (um conto, oitocentos e sessenta mil, seiscentos e setenta e quatro réis).

A mobília de sua casa não era tão escassa como verifiquei em outros inventários sergipanos como por exemplo, o de Antonio Teixeira de Souza que deixou de mobília para a sua esposa, uma caixinha. De um modo geral, a modéstia e a escassez do mobiliário, fato que nos chama a atenção pela inexistência de espaços aconchegantes para o convívio familiar, mas é importante notar que essa era uma característica dos lares desse período. "A precariedade do mobiliário e dos ambientes domésticos era comum a toda a Colônia, salvo algumas poucas exceções, como as casas de certos capitães-mores e de alguns ricos fazendeiros" (ALGRANTI, 1997, p. 105).

A mobília de Antonio Cazimiro era composta dos seguintes itens: 06 cadeiras de encosto, 03 cadeiras de encosto falho, 01 bofete de jacarandá, 01 caixa, 01 arca, 01 cama de jacarandá, caminha, catre, 02 espelhos de compor com os vidros quebrados, 01 banco de desposo de madeira branca, 04 bancos grandes, 01 mesa grande com gavetas, 03 bancos de encosto bem grandes. Isso não era pouco para a época. A mobília e os utensílios domésticos da casa de Antonio Cazimiro vão fazer a diferença no que se refere ao padrão das casas coloniais sergipanas que tinham o seu mobiliário escasso. Percebo também um grau de refinamento não somente na mobília, como também nos utensílios domésticos, que eram compostos de: 06 colheres de prata, uns pratos finos, 05 tachos de cobre, 01 sopeira grande da Îndia, 06 pratos finos rasos, 01 candeeiro de latão, 01 castiçal de latão, 06 frascos. A vida cotidiana desse livreiro destoa da realidade apresentada por Algranti (1997), que era muito comum, na maior parte dos lares coloniais comer com as mãos, pois, quase não havia facas, colheres, pratos e copos. "Garfos, então, se já eram raros no Reino e em quase toda Europa, na Colônia praticamente não existem. Seu uso só será generalizado no século XIX" (ALGRANTI, 1997, p. 122).
Conforme consta na partilha dos bens, Jozefa Maria de Serqueira deixou quatro herdeiros, dos quais identifiquei o nome de três: uma já casada, Ana, com Antonio Damasceno. Diferentemente dos demais, Ana não teve, a sua idade revelada, no inventário, talvez fosse emancipada, ou maior de idade. Os outros dois herdeiros, o documento nos permite saber que eram menores de idade ${ }^{4}$ : Jozefa, com a idade de dezessete anos e Manoel, com a idade de dez anos. Registro que é desse modo que os nomes dos filhos de Antonio Cazimiro aparecem no inventário.

Em seu inventário ficou o registro de uma livraria, pois assim está escrito no documento, com quinhentos livros diversos, entre velhos e novos, pequenos e grandes, no valor de quatro mil réis. Provavelmente, essa livraria estava localizada em uma de suas duas casas, situadas na cidade de São Cristóvão sendo uma "[...] morada di caza di sobrado com huma parede de pedras ate ivergamentto da parte da rua com pilares com a terça detrás a ruinada" 0 inventário mostrou ainda, que a referida morada "[...] cita na rua Sam Francisco desta cidade de Sam Cristovam [ilegível] da Santa caza de Misericórdia” (SERGIPE, 2005, p. 06. CD-ROM 1). A outra "morada di caza di sobrado cita na rua Sam Bento por acabar” (SERGIPE, 2005, p. 11. CD-ROM 1).

Essas duas casas tinham uma localização privilegiada na cidade, principalmente a primeira, porque pela avaliação dos bens, era a mais cara e estava orçada em cento e oitenta mil réis, enquanto que a outra casa, também de sobrado, situada na rua São Bento foi avaliada em cem mil réis. Considerando que a casa da rua São Bento estava inacabada, a livraria ocupou a casa de sobrado da rua São Francisco, sendo esse também, o espaço mais central da cidade. Percebe-se nesse registro, não somente o tipo arquitetônico da casa,

\footnotetext{
4 As Ordenações expressam em seus diversos títulos, que a menor idade era de 25 anos, como se observa: "[...] se fallecer algum, que tenha filhos menores de 25 annos, o Juiz dos órfãos terá cuidado, do dia do seu falecimento a um mez, fazer inventário de todos os bens moveis e de raiz que por morte do defunto ficarem" (Ordenações Filipinas, Livro 1, Titulo LXXXVII, p. 207-208).
} 
mas o tipo de material empregado na sua construção, elementos que não devem ser desprezados na análise, pois a "casa é o palco permanente das atividades condicionadas à cultura de seus usuários" (ALGRANTI, 1997, p. 90). A casa de sobrado também revela o seu significado e ainda diz muito dos seus moradores, pois era ocupada pelos membros da elite e surgiram mais tarde, em conseqüência da diversificação da economia e do crescimento urbano. 0 espaço do sobrado era muitas vezes constituído de "[...] um soalho suspenso, o que, portanto, podia indicar que estava acima - forros assoalhados - ou embaixo do piso, chegavam a ter dois ou mais andares" (ALGRANTI, 1997, p. 101).

Geralmente esse tipo de casa tinha instalado em seu primeiro pavimento a loja, ou escritório. Acredito que no caso de Antonio Cazimiro a sua livraria estava instalada no primeiro pavimento impedindo que os estranhos se introduzissem nos espaços de convívio da família. Aqui percebo uma certa noção de privacidade.

\begin{abstract}
Tais cômodos tinham função semelhante ao alpendre e varandas das casas de sítios ou casas térreas, embora esses últimos servissem também de área de circulação. No segundo andar, instalavam-se a sala e os quartos de tamanhos geralmente reduzidos, e no último a cozinha. Os escravos poderiam estar no sótão, ou no porão junto às cavalariças (ALGRANTI, 1997, p. 101).
\end{abstract}

É importante registrar que a existência de uma livraria na cidade de "burocratas e religiosos", denuncia a circularidade de idéias daqueles que compunham os círculos mais estreitos de poder. Esse poder se impunha pela ocupação dos seguintes cargos: "Capitão-mor, Ouvidor, Tabelião, Inquiridor, Contador e distribuidor, Alcaide, Carcereiro e Almotacés" (NUNES, 1996, p. 171). Ainda conforme a referida autora, os religiosos integraram esse núcleo social. Esse grupo, denominado de elites locais “[...] que por sua posição social, figuraram entre os grupos de maior status, poder e renda [...]" (VELLASCO, 2004, p. 213). Dentro desse entendimento, os grupos

5 Expressão utilizada por Thetis Nunes para caracterizar a cidade de São Cristóvão. de elites são diversos, tais como: “'os dirigentes', 'as pessoas influentes', 'os abastados', ou os 'privilegiados', e isto, na maior parte dos casos, sem uma outra forma de justificação, uma vez que o poder da elite impor-se-ia por si próprio e prescindiria de maiores explicações" (HEINZ, 2006, p. 8).

Considerando esse princípio, é possível compreender o lugar social que Antonio Cazimiro Leite ocupou na sociedade de São Cristóvão. Assim, ocupando a função de livreiro expressou a sua singularidade, mas também a sua liberdade de interagir, de negociar com homens de seu tempo, criando uma "cadeia de interdependência” (CHARTIER, 1990, p. 101). Cadeia essa, que o ligou aos outros homens e provavelmente, estendeu-se ao Reino.

No inventário de Josefa Maria de Serqueira, a partir das dívidas dos credores é possível perceber a cadeia de interdependência que se formou em torno de Antonio Cazimiro, mostrando que o mesmo mantinha laços estreitos com o grupo do poder local: Coronel Francisco Xavier de Oliveira, Capitão-mor Francisco Felis Barreto, Capitão Luiz Francisco Freire, Capitão Romoaldo Barboza de Serqueira, Capitão Francisco Argolo. Pelos cargos que ocupavam, percebe-se que esse grupo tinha o maior status local, ou seja, era um grupo que detinha um certo poder, resultado de uma seleção social ou intelectual.

Essas patentes dizem muito sobre a posição que essas pessoas ocupavam na sociedade setecentista sergipana, pois não era todo indivíduo que alcançava tal distinção. Para a obtenção de tais ofícios e patentes era preciso ter grande poder de influência, que "[...] dependia-se de algum apadrinhamento de algum indivíduo poderoso no Reino" (FURTADO, 2006, p. 52). "A prática de favorecimento de ofícios e patentes provocava o estabelecimento de cadeias de clientelismo as quais, ao mesmo tempo, aumentavam o poder daqueles que concedia os favores" (FURTADO, 2006, p. 52). Além do mais,

[...] a constituição de um corpo de fun- 
cionários era peça relevante da ação do poder monárquico, por isso constituía-se uma de suas principais prerrogativas, a criação e nomeação de cargos e patentes. Em diversos momentos, ficava evidente que o Rei recorria à distribuição de cargos em troca da fidelidade de alguns súditos e para ampliar sua justiça às regiões mais distantes (FURTADO, 2006, p. 49).

Nessa dinâmica de relações convém perguntar de onde vinham os livros que eram vendidos na livraria de Antonio Cazimiro Leite, considerando que "os textos em circulação no Brasil desde o século XVI e até 0 início do século XX, mesmo os de autores brasileiros, eram predominantemente produzidos em Portugal, onde a imprensa tipográfica fora introduzida desde 1487"6? Intelectuais portugueses como Valentim Magalhães costumavam afirmar: "o Brasil é o melhor mercado de livros lusitanos"7. Então é possível supor que o livreiro tinha um vínculo estabelecido com o Reino português que envolveu não somente as atividades mercantis, mas a veiculação dos códigos culturais da metrópole, através dos livros vendidos.

Considerando aquele vínculo como Antonio Cazimiro Leite movimentou o seu negócio e fez as suas encomendas para atender seus clientes? Como ele negociou e pôs em prática, as estratégias de divulgação dos livros? E ainda como ele se dividiu entre a atividade de livreiro, de administrador e detentor de terras e de escravos e a advocacia?

Dentro desse propósito, ressalto a importância do livreiro, utilizando as palavras de Darnton quando chamou a atenção para o seguinte aspecto [...] é preciso estudar melhor o livreiro enquanto agente cultural, o intermediário entre a oferta e a demanda em seu

6 NASCIMENTO, Jorge Carvalho do. "Nota prévia sobre a palavra impressa no Brasil do século XIX: a biblioteca do povo e das escolas". In: Horizontes. Bragança Paulista: Centro de Documentação e Pesquisa em História da Educação. v. 19, 2001. p. 12.

7 Idem, ibidem. p. 12 principal ponto de conexão (DARNTON, 1990, p. 126).

Desse modo, o livreiro deve ser entendido como um agente cultural, importante no processo de difusão e de circulação dos materiais impressos e no caso de São Cristóvão, centro de burocratas e religiosos não nos surpreende o fato de ter existido uma livraria, nos anos setecentos, com quinhentos livros. Entendo que "toda atividade social que, em uma sociedade, criou para si mesma uma estrutura e à qual um grupo de homens se dedicou de maneira especial, corresponde seguramente a uma necessidade da vida dessa sociedade" (MICELI, 1982. p. XXII).

Partindo desse sentido, percebo a referida livraria como uma necessidade criada pela própria estrutura daquela cidade que certamente, tinha um público consumidor dos impressos de Antonio Cazimiro. Então, é sob a lente da circulação de idéias e da cultura que focalizo a São Cristóvão setecentista.

Porém ainda tenho muitas perguntas sem respostas, às quais os livros arrolados nos inventários, não ajudam a responder, pois no documento analisado, não consta a relação ou descrição dos mesmos, apenas que tinham 500 livros, sem mencionar quais eram.

Mas qual o valor desses livros no conjunto dos bens de Antonio Cazimiro Leite? Em relação a esse fato, Abreu (2001) tem muito a nos dizer ao revelar que ao contrário do que se pensa, os livros eram objetos baratos ou muitas vezes, na visão dos avaliadores dos bens eram considerados objetos sem valor,

[...] guardadas as diferenças de valor e função dos formatos e tipos de encadernação, os impressos, ao contrário do que se imagina, eram coisas baratas. Dentre os bens avaliados nos inventários, o livro era o que possuía valor unitário dos mais baixos, podendo chegar a ser considerado "sem serventia" pelos avaliadores. Obras como "Vida de Dom Nuno Alvares Pereira", "Predestinado Peregrino", "Hum livro de Sermoens", "Catecismo de Monte Pelier" foram consideradas "sem valor" [...] (ABREU, 2001, CD-rom). 
Abreu (2001) mencionou que nos inventários analisados, foi possível localizar uma outra mercadoria inferior aos livros: "hum par de botas rotas sem valor". Por outro lado, essa autora fez a seguinte indagação: muito caros para os pobres e muito baratos para os ricos, a quem interessariam ou para quem seria possível manter livros em casa? Segundo Villata (1999), os livros "[...] subsidiavam com suas informações o exercício de profissões, constituíam meios de acesso às "verdades sagradas" e também eram objeto de deleite, de recreio" (VILALTA, 1999, p. 198) e ainda era objeto de status e de poder. Fora do âmbito das profissões "os leitores potenciais seriam os cidadãos de relevo social, aqueles da estreita fatia detentora do poder econômico" (ARAÚJO, 1999, p. 241). Abreu reafirmou essa idéia ao entender que, "financeiramente, os livros não deveriam ser objeto de muita preocupação, ao menos no caso das pessoas de posses, cujos bens de outra natureza superavam largamente o valor das obras impressas" (ABREU, 2001, Cd-rom). Como é o caso do nosso livreiro de São Cristóvão cuja livraria detinha valor muito inferior ao montante de sua fortuna. Ainda conforme essa autora,

[...] para as pessoas de posses, os impressos não tinham relevância no montante dos bens, mas para os menos aquinhoados pela fortuna, eles poderiam ser considerados caros. Se um livro custava em torno de $1 \$ 000$ por volume, era preciso ter uma renda razoável para poder constituir uma biblioteca (ABREU, 2001, Cd-rom).

Comparando o valor dos livros de Antonio Cazimiro Leite em relação a alguns de seus bens, identificados no inventário de sua esposa fica mais nítido o valor da livraria, no âmbito da sua fortuna.

0 valor da livraria com 500 livros era de quatro mil réis e entre os bens identificados no inventário, a sua maior parte tinha um valor superior aos livros: morada de casas de sobrado com uma parede de pedras na rua São Francisco, no valor de cento e oitenta mil réis, uma morada de casas de sobrado na rua São Bento e um sítio de terras com casa de telhas com setenta coqueiros, ambos avaliados em cem mil réis, cada um, um mestiço no valor de setenta mil réis, um negro de nome Manuel avaliado em sessenta mil réis, uma escrava mulata no valor de vinte e cinco mil réis, um cavalo russo de vinte mil réis, colheres de prata avaliadas em sete mil e quinhentos mil réis. Os bens de valores aproximados ao valor da livraria são o bofete de jacarandá com duas gavetas, avaliado em cinco mil réis, uma rede de varanda de três mil e duzentos réis e um par de fivelas de prata de sapatos de três mil e duzentos réis.

Talvez os avaliadores, por não serem especializados no trato com os livros, não avaliaram minuciosamente as obras e por isso não lhe atribuíam o valor adequado. É curioso observar ainda o valor da livraria que era de quatro mil réis, em relação ao valor gasto com as dívidas do funeral, de Josefa Maria Serqueira que custou cento e vinte e oito mil réis.

Então, a quem eram vendidos esses livros? É possível vislumbrar o perfil de um leitor na época? Um leitor sim, o Reverendo Padre Domingos Vieira de Mello $^{8}$, mas não o seu perfil, como leitor devido a falta de fontes, pois até o presente momento não consegui encontrar o inventário do mesmo. Este leitor se fez presente nas dívidas do funeral de Jozefa Maria de Serqueira, como mostra o inventário:

\begin{abstract}
Diz Ant Cazimiro Leite $q^{\text {e }}$. esta procedendo o inventro dos bens de sua defunta $\mathrm{m}^{\mathrm{er}}$ em juizo. $\mathrm{E}$ por que no seu funeral se fizerão os gastos q constão dos docu$\mathrm{m}^{\text {tos }}$ juntos pertende se mantem juntar ao inventro para se separarem bens para ele como taobem deixaram o sup $^{\text {te }}$ que entre quinhentos corpos de livros que inventariarão fez uma partida de uma Istoria Ecleziastica em 68 tomos pequenos que ainda se esta devendo o $\mathrm{R}^{\text {do }} \mathrm{Pe}^{\mathrm{e}} \mathrm{Dom}^{\circ}{ }^{\mathrm{s}} \mathrm{V}^{\mathrm{a}}$ de Mello e se deve carcular no valor da mesma livraria abater dessa $53 \$$ res $\mathrm{p}^{\mathrm{r}} \mathrm{q}$ o suplicante os comprou (SERGIPE, 2005, p. 19. CD-ROM 1).
\end{abstract}

O Reverendo Padre Domingos Vieira de Mello comprou 68 tomos ${ }^{9}$ pequenos de História Eclesiástica, no valor cinqüenta e três mil réis. Pelo inventário,

8 O seu inventário não foi localizado, até o presente momento.

9 Cada um dos volumes de uma obra científica ou literária Língua portuguesa on-line. Disponível em http://www.priberam.pt/dlpo/dlpo.aspx. Acesso em 29 de maio de 2008 
percebe-se que o padre não efetuou o pagamento de sua dívida, no ato da compra. Ficou registrado no documento analisado que essa dívida do padre deveria cobrir parte das despesas com o funeral de Josefa Maria de Serqueira. Em relação ao padre, deixo mais uma lacuna nesse texto, que se constrói à medida em que encontro os rastros, os fragmentos, os indícios deixados por atores que viveram àquele tempo.

A existência desse leitor reafirma a tese de Araújo (1999) quanto à circulação de livros no Brasil período colonial. No caso dos leitores, o maior problema é conseguir rastreá-los, considerando que os mesmos deixaram poucos indícios de suas leituras.

Considerando a influência Iluminismo e a ascensão e queda do Marquês de Pombal, que imprimiu a sua marca no âmbito das reformas por ele instituídas, na Corte portuguesa, não mudou a prática do leitor desse momento, pois Araújo menciona que "[...] os documentos de que dispomos indicam um leitor apenas refletido a partir das áreas diretamente oriundas de um interesse específico de ampliação de status acadêmico e profissional" (ARAÚJO, 1999, p. 61-62). Muito embora o autor tenha encontrado registro da circulação de alguns clássicos latinos, gramáticas e dicionários, o que predominava eram as obras de devoção. A História Eclesiástica citada no inventário de Josefa Maria de Serqueira está inserida no âmbito da circulação de livros sacros.

Ainda me reportando a Araújo (1999), busco elementos para tratar dessa obra. 0 autor aponta pistas de uma possível autoria do livro mencionado, ao analisar o "único inventário de livros, do século XVIII, do bispo D. Thomas da Encarnação Costa Lima, de 5 de maio de 1784 e acrescentou que [...] o mesmo D. Thomas $^{10}$, segundo Pereira da Costa, mourejava em Olinda na metade do século e era autor de uma História ecclesiástica lusitana (ARAÚJO, 1999, p. 64).

Alguns livros [...] "vão ser popularíssimos nas livra-

10 Regalista militante, o bispo fora pregador em uma oração pela boa saúde de Pombal em 1776 e teve papel relevante na desenvoltura das reformas pombalinas na instrução pública de Pernambuco (ARAÚJO, 1991, p. 64). rias setecentistas, como a própria História eclesiástica de Claude Fleuri (1640-1723), traduzida em português, em 1753 e também conhecida como Catecismo histórico" (ARAÚJO, 1999, p. 338). Esse autor verificou também que para a escola secundária, no século XVIII, o programa de disciplinas e leituras dos oratorianos estava diluído em três secções: Latim, Poética e Retórica e a História e Geografia. É nessa última secção que a História Eclesiástica se fez presente, "nos exercícios da língua latina portuguesa" a obra recomendada integrou a "parte $2^{\mathrm{a}}$ da História eclesiástica. Para uso das escolas do Oratório na Casa de Nossa Senhora das Necessidades"' (ARAÚJO, 1991, p. 99). Ainda nessa última secção Araújo fez outra menção aos Princípios da História eclesiástica, escritos em forma de diálogos.

É difícil saber qual seria o verdadeiro título da obra citada no inventário de Jozefa Maria de Serqueira, até mesmo porque não era costume dos avaliadores dos bens anunciarem o nome completo dos livros inventariados. Mas o estudo de Araújo nos revelou que as Histórias eclesiásticas citadas circularam no século XVIII, em Recife e a partir do inventário de Antonio Cazimiro Leite, mostro também que uma certa História eclesiástica circulou também em Sergipe. A partir dos elementos analisados, chamo atenção para o fato de que aí está caracterizada a circularidade da obra, que conforme Villalta (1999),

\section{[...] auxiliavam os fiéis a praticar suas devoções religio- sas, a assistir aos ofícios sagrados e a se preparar para o sacramento da penitência, corrobora aquela utilidade já inferida a partir dos inventários e das listas de livros enviados da América para o Reino: assim como alguns livros, os impressos baratos permitiam o acesso dos lei- tores às verdades sagradas e às práticas das cerimônias e ritos religiosos (VILLALTA, 1999, p. 203).}

Ainda conforme esse autor, os "usos explícitos" dos livros denunciam a importância desse objeto como ornamento e as suas potencialidades como elemento de poder "[...] o uso do livro como um privilégio, não apenas no sentido econômico, mas cuja posse e leitura eram, muitas vezes, um direito exclusivo de grupos sociais determinados e seletos" (VILALTA, 1999, p. 212). 


\section{CONCLUSÃO}

O livreiro na São Cristóvão setecentista certamente foi um agente cultural importante no processo de difusão e de circulação dos materiais impressos e ain$\mathrm{da}$, de modelos de comportamento, apesar da historiografia sergipana revelar que a população da referida cidade era essencialmente rural e pouco letrada. Observando sob essa lente seria difícil perceber a livraria de Antonio Cazimiro Leite.

Acredito que a livraria foi um estabelecimento comercial da maior importância da vida são cristovense setecentista localizada, provavelmente, na Rua São Francisco, onde congregava outras construções importantes, como por exemplo, a Santa Casa de Misericórdia. Numa casa de sobrado com um muro de pedras até o envergamento da rua, essa construção arquitetônica, destoava das palhoças mencionadas pela professora Thetis.

Araújo (1999) em O perfil do leitor colonial, não fez menção da existência de livrarias ou bibliotecas no período da colônia e sim no século XIX, no qual constatou que Manoel Clemente Cavalcante de Albuquerque tinha uma expressiva biblioteca em 1826, na cidade de São Cristóvão. Diante disso, é provável que a livraria de Antonio Cazimiro Leite tenha sido o primeiro estabelecimento dessa natureza existente na Capitania de Sergipe Del Rey.

É preciso lembrar que a descrição e a avaliação dos bens, no inventário de sua esposa, possibilitam apreender o grau de refinamento da família desse livreiro pelos utensílios domésticos: sopeira da índia, colheres de prata; pela mobília: cama, mesa com gavetas, bofete de jacarandá. Esses elementos aliados aos demais bens revelam o perfil no micro-cosmo sócio-econômico-cultural da cidade.

Ainda nos foi possível vislumbrar um leitor, o Reverendo Padre Domingos Vieira de Mello que comprou 68 tomos pequenos de História Eclesiástica, no valor cinqüenta e três réis. Essa evidência nos dá ainda subsídios para a compreensão da prática do comércio de livros e da existência de um mercado consumidor desses bens culturais no século XVIII na cidade de São Cristóvão, da Capitania de Sergipe Del Rei. Tais evidências confirmam ainda, a idéia de circularidade dos livros que eram a fonte do saber profissional, do saber eclesiástico e de entretenimento, no período colonial sergipano.

\section{REFERÊNCIAS}

ALGRANTI, Leila Mezan. Famílias e vida doméstica. In: SOUZA, Laura de Mello e (Org.) História da vida privada no Brasil: cotidiano e vida privada na América portuguesa. São Paulo: Companhia das Letras, 1977. p. 84-154(História da vida privada no Brasil I)

ARAÚJO, Jorge de Souza. Perfil do leitor colonial. Ilhéus: UESC, 1999.
ABREU, Márcia. Quem lia no Brasil Colonial? In: Congresso Brasileiro da Comunicação INTERCOM: A mídia impressa, o livro e o desafio das novas tecnologias - Sociedade Brasileira de Estudos Interdisciplinares da Comunicação, 2001. Campo Grande. Anais eletrônicos do XXIV Congresso Brasileiro da... Disponível em: http://www.intercom.org.br/papers/nacionais/2001/arquivos/np04.htm\#abreuquem. Acesso em 27 de maio de 2008. CHARTIER, Roger. Formação 
social e habitus: uma leitura de Norbert Elias In: CHARTIER, Roger. A História Cultural: entre práticas e representações. 1990. Lisboa: Difel: Rio de Janeiro: Editora Bertrand Brasil, S. A.

DARNTON, Robert. Os leitores respondem a Rousseau: a fabricação da sensibildade romântica. In: DARNTON, Robert. $\mathbf{O}$ grande massacre de gatos. Rio de Janeiro: Graal. 1986. p. 277-328.

DARNTON, Robert. 0 que é a história dos livros? In: DARNTON, Robert. 0 beijo de Lamourette: mídia, cultura e revolução. Trad. Denise Bottman. São Paulo: Companhia das Letras. 1990. p. 109-172.

FARIA, Sheila de Castro. A colônia em movimento: fortuna e família no cotidiano colonial. Rio de Janeiro: Nova Fronteira, 1998.

FURTADO, Júnia Ferreira. Homens de negócio: a interiorização da metrópole e do comércio nas minas setecentistas. São Paulo: Hucitec, 2006.

HEINZ, M. Flávio.(Org.) Por outra história das elites. Rio de Janeiro: FGV, 2006.

LOPES, Eliane Marta Teixeira; GALVÃO, Ana Maria de Oliveira. História da Educação. Rio de Janeiro: DP\&A, 2001.

Língua portuguesa on-line. Disponível em http:// www.priberam.pt/dlpo/dlpo.aspx. Acesso em 29 de maio de 2008.

MAGALHÃES, Valentim. Litteratura brasileira (18701895). Rio de Janeiro, Lisboa: Livraria de Antonio Maria Pereira, 1896.
MAXWELL, Kenneth. Marquês de Pombal: paradoxo do Iluminismo. Tradução: Antonio de Pádua Donesit. Rio de Janeiro: Paz e Terra, 1996.

MICELI, Sérgio. (Org.) A força do sentido. In: Pierre Bourdieu. A economia das trocas simbólicas. Editora Perspectiva. São Paulo: Editora Perspectiva, 1982. p. I-LXI.

NASCIMENTO, Jorge Carvalho do. “Nota prévia sobre a palavra impressa no Brasil do século XIX: a biblioteca do povo e das escolas". In: Horizontes. Bragança Paulista: Centro de Documentação e Pesquisa em História da Educação. v. 19, 2001.

NUNES, Maria Thetis Sergipe Colonial II. Rio de Janeiro: Tempo Brasileiro, 1996.

PODER JUDICIÁRIO DO ESTADO DE SERGIPE. Arquivo Geral do Poder Judiciário. Inventário de Jozefa Maria de Serqueira. In: Catálogo Digital da documentação do século XVIII de Sergipe: inventários judiciais - São Cristóvão, Maruim e Lagarto 2005. CD-ROM 1.

VELLASCO, Ivan de Andrade. As seduções da ordem: violência, criminalidade e administração da Justiça: Minas Gerais - século 19. São Paulo: EUSC, 2004. (Coleção História)

VILLALTA, Luiz Carlos. Os leitores e os usos dos livros na América portuguesa. In: ABREU, Márcia. (Org.) Leitura, História e História da leitura. São Paulo: FAPESP, 1999. p.183-212.

UNIVERSIDADE DE COIMBRA. Ordenações Filipinas. Livro 1, Titulo LXXXVIII Disponível em http://www. uc.pt/ihti/proj/filipinas/ordenacoes.htm. Acesso em 21 abr. 2008. 
1 Doutora em Educação do Núcleo de Pós-graduação em Educação da UFS. E-mail: veramstos@yahoo.com.br 